\title{
INVARIANCE OF DISTRIBUTIONAL CHAOS FOR BACKWARD SHIFTS
}

\author{
XINXING Wu AND YANG LUO
}

Abstract. A sufficient and necessary condition ensuring that the backward shift operator on the Köthe sequence space admits an invariant distributionally $\varepsilon$-scrambled set for some $\varepsilon>0$ is obtained, improving the main results in [10].

Mathematics subject classification (2010): 47A16.

Keywords and phrases: Backward shift, Köthe sequence space, distributional chaos, invariant set.

\section{REFERENCES}

[1] T. Bermúdez, A. Bonilla, F. Martínez-Giménez, A. Peris, Li-Yorke and distributionally chaotic operators, J. Math. Anal. Appl. 373, (2011), 83-93.

[2] N. C. Bernardes JR., A. Bonilla, V. Müller, A. Peris, Distributional chaos for linear operators, J. Funct. Anal. 265, (2013), 2143-2163.

[3] J. BÈs, Invariant manifolds of hypercyclic vectors for the real scalar case, Proc. Amer. Math. Soc. 127, (1999), 1801-1804.

[4] B. Du, On the invariance of Li-Yorke chaos of interval maps, J. Difference Equ. Appl. 11, (2005), 823-828.

[5] M. Goliński, Invariant subspace problem for classical spaces of functions, J. Funct. Anal. 262, (2012), 1251-1273.

[6] G. Godefroy, J. H. Shapiro, Operators with dense, invariant, cyclic vector manifolds, J. Funct. Anal. 98, (1991), 229-269.

[7] G. KÖTHE, Topological Vector Space. I, translated from German by D. J. H. Garling, Die Grundlehren der mathematischen Wissenschaften, Band 159, Springer-Verlag New York Inc., New York, 1969.

[8] F. MARtíneZ-GiméneZ, Chaos for power series of backward shift operators, Proc. Amer. Math. Soc. 135, (2007), 1741-1752.

[9] F. MARTíneZ-GiméneZ, A. PERis, Chaos for backward shift operators, Int. J. Bifurcation and Chaos 12, (2002), 1703-1715.

[10] F. Martínez-Giménez, P. Oprocha, A. Peris, Distributional chaos for backward shift, J. Math. Anal. Appl. 351, (2009), 607-615.

[11] P. Oprocha, A quantum harmonic oscillator and strong chaos, J. Phys. A: Math. Gen. 39, (2006), 14559-14565.

[12] P. Oprocha, Invariant scrambled sets and distributional chaos, Dyn. Syst. 24, (2009), 31-43.

[13] C. J. READ, A solution to the invariant subspace problem, Bull. London Math. Soc. 16, (1984), 337401.

[14] C. J. READ, The invariant subspace problem for a class of Banach spaces. II. Hypercyclic operators, Israel J. Math. 63, (1988), 1-40.

[15] B. SCHWEIZER, J. Smítal, Measures of chaos and a spectral decomposition of dynamical systems on the interval, Trans. Amer. Math. Soc. 344, (1994), 737-754.

[16] X. Wu, Maximal distributional chaos of backward shift operators on Köthe sequence spaces, Czechoslovak Math. J. 64, (2014), 105-114.

[17] X. Wu, G. CHEN, On the invariance of maximal distributional chaos under an annihilation operator, Appl. Math. Lett. 26, (2013), 1134-1140.

[18] X. Wu, G. CHen, P. ZHU, Invariance of chaos from backward shift on the Köthe sequence space, Nonlinearity 27, (2014), 271-288. 
[19] X. WU, L. WANG, G. CHEN, Weighted backward shift operators with invariant distributionally scrambled subsets, Ann. Funct. Anal. 8, (2017), 199-210.

[20] X. WU, X. ZHANG, X. MA, Various shadowing in linear dynamical systems, Int J. Bifurcation and Chaos 29, (2019), 1950042 (10 pages).

[21] X. WU, P. ZHU, The principal measure of a quantum harmonic oscillator, J. Phys. A: Math. Theor. 44, (2011), 505101 (6pp).

[22] X. WU, P. ZHU, On the equivalence of four chaotic operators, Appl. Math. Lett. 25, (2012), $545-549$.

[23] X. WU, P. ZHU, Li-Yorke chaos for backward shift operators on Köthe sequence spaces, Topology Appl. 160, (2013), 924-929.

[24] X. WU, P. ZHU, Invariant scrambled set and maximal distributional chaos, Ann. Polon. Math. 109, (2013), 271-278.

[25] Z. Yin, Z. Chen, Y. Chen, X. Wu, Perturbation of distributionally chaotic operators, Rev. R. Acad. Cienc. Exactas Fís. Nat. Ser. A Math. RACSAM, accepted for publication. 